\title{
SIGNIFICADOS ATRIBUÍDOS POR PUÉRPERAS ADOLESCENTES À MATERNIDADE: AUTOCUIDADO E CUIDADO COM O BEBÊ
}

\author{
Luciane Amorim da Silvaํ, Ana Márcia Spanó Nakano², Flávia Azevedo Gomes³, Juliana Stefanello
}

\footnotetext{
${ }^{1}$ Enfermeira obstétrica do Hospital São Luis. São Paulo, Brasil. E-mail: lucianeeerp@yahoo.com.br

${ }^{2}$ Doutora em Enfermagem. Professor Associado do Departamento de Enfermagem Materno-Infantil e Saúde Pública da Escola de Enfermagem de Ribeirão Preto da Universidade de São Paulo (EERP/USP). São Paulo, Brasil. E-mail: nakano@eerp.usp.br

${ }^{3}$ Doutora em Enfermagem em Saúde Pública. Professor Doutor do Departamento de Enfermagem Materno-Infantil e Saúde Pública da EERP/USP. São Paulo, Brasil. E-mail: flagomes@eerp.usp.br

${ }^{4}$ Doutora em Enfermagem em Saúde Pública. Professor Doutor do Departamento de Enfermagem Materno-Infantil e Saúde Pública EERP/USP. São Paulo, Brasil. E-mail: julianas@eerp.usp.br.
}

\begin{abstract}
RESUMO: Os objetivos foram identificar os significados atribuídos pelas mães adolescentes aos cuidados com o bebê e seu autocuidado; identificar os que reconhecem como dificuldade na vivência da fase puerperal e no cuidado com o bebê. Estudo qualitativo realizado em uma maternidade de atendimento do Sistema Único de Saúde, de janeiro a março de 2005. Participaram 22 puérperas adolescentes primíparas. Os dados foram coletados por entrevistas semi-estruturadas, gravadas, com posterior análise de conteúdo do tipo temática. A maternidade é percebida como uma mudança psicológica, social e física, e o cuidado materno, como um dever a ser exercido, sendo prioritário em relação ao cuidado de si mesmo. A falta de experiência, informação e a situação financeira foram apontadas como principais dificuldades para o cuidado, sendo a família o suporte. A sociedade subestima a capacidade da adolescente para cuidar do filho, devendo criar estratégias para o desenvolvimento da autonomia da adolescente, para que esta assuma ativamente as responsabilidades maternas.
\end{abstract}

DESCRITORES: Saúde da mulher. Saúde do adolescente. Período pós-parto. Autocuidado.

\section{MEANING ATTRIBUTED BY ADOLESCENTS PUERPERAE CONCERNING MATERNITY: SELF-CARE AND BABY'S CARE}

\begin{abstract}
The objectives of this study were to identify the meanings attributed by adolescent mothers towards care for their babies and self-care, and to identify what they recognize as difficulties during their postpartum period and concerning caring for their respective babies. This study used a qualitative approach that took place in a maternity hospital that attends women through the Brazilian National Health Care System (Sistema Único de Saúde) from January to March of 2005. The subjects were 22 adolescent first time pregnant women. The data was collected via semi-structured interviews, recorded, and submitted to posterior thematic content analysis. Maternity is understood as a psychological, social, and physical change with maternal care as a duty to be exercised, taking priority when compared with self-care. The lack of experience, information, and their financial situations were pointed out as the main difficulties to care, with family listed as support. Society underestimates the adolescent's capacity to care for the child, needing to create strategies for developing the adolescent's autonomy in order that she actively assume her maternal responsibilities.
\end{abstract}

DESCRIPTORS: Women's health. Adolescent health. Postpartum period. Self care.

\section{SIGNIFICADOS ATRIBUIDOS POR PUÉRPERAS ADOLESCENTES A LA MATERNIDAD: AUTOCUIDADO Y EL CUIDADO CON EL BEBÉ}

RESUMEN: Los objetivos del estudio fueron: identificar los significados atribuidos por las madres adolescentes al cuidado del bebé y de sí mismas; e identificar lo que reconocen como dificultad en el puerperio y en el cuidado del bebé. Es un estudio cualitativo desarrollado de Enero a Marzo de 2005, en una maternidad que atiende a usuarias del Sistema Único de Salud. Participaron 22 puérperas adolescentes y primíparas. Los datos fueron recolectados por entrevistas parcialmente estructuradas, grabadas, con posterior análisis del contenido de tipo temático. La maternidad es vista como un cambio psicológico, social y físico, y el cuidar del bebé es como un deber a ser ejecutado, como prioridad en relación al cuidado de sí. La falta de experiencia, información y la situación financiera fueron señaladas como las principales dificultades para el cuidado del niño, siendo la familia el apoyo. La sociedad subestima la capacidad de la adolescente para cuidar del hijo, debiendo crear estrategias para el desarrollo de autonomía para que la adolescente asuma las responsabilidades maternas.

DESCRIPTORES: Salud de la mujer. Salud del adolescente. Periodo de posparto. Autocuidado. 


\section{INTRODUÇÃO}

A maternidade na adolescência tem merecido atenção especial nos últimos tempos, em razão do número expressivo desta ocorrência em nossa sociedade. Na tentativa de identificar pontos críticos deste evento e seus determinantes, a gravidez na adolescência é analisada sob diferentes pontos de vista.

A gravidez na adolescência é abordada como um problema de saúde pública. Nessa perspectiva, a gravidez estaria inserida em um contexto de desvantagem social para as adolescentes e resultaria da falta de acesso à informação e aos serviços de saúde. Ainda sob esta ótica, é muitas vezes considerada como um reforço à pobreza e à marginalidade, inserida em um contexto de desvantagem social para as adolescentes. Assim, sua ocorrência já se daria num âmbito pontuado por oportunidades restritas, poucas opções de vida e estaria marcada por interrupções na trajetória escolar. ${ }^{1}$ A gravidez na adolescência pode ser um fator de limitação para a adolescente no que tange à educação, ao trabalho, ao matrimônio e a perspectivas futuras. ${ }^{2}$ Uma das privações que a maternidade acarreta na vida da adolescente está na formação educacional, frequentemente interrompida, gerando atrasos na vida estudantil e distanciamento do grupo de convivência. ${ }^{3}$

Entretanto, alguns autores consideram que se referir a este evento como um "problema" constitui-se em uma visão reducionista e pode expor as adolescentes a riscos e preconceitos adicionais. ${ }^{4}$ Estudos têm apontado a maternidade na adolescência como um evento almejado pelas jovens, sendo um projeto de vida, o que é um indicativo de mudança nos padrões de reprodução, resultante do desejo das mulheres e de suas famílias de iniciarem mais cedo sua vida reprodutiva. ${ }^{5}$

Ao privilegiar a idade, como elemento fundamental de análise da ocorrência da gravidez na adolescência, desconsideram-se as diferenças sociais, que marcam de forma distinta as etapas da vida humana e as múltiplas e variadas implicações que o evento produz sobre as trajetórias das meninas e suas redes familiares. E, ainda, obscurece a assimetria nas relações de gênero e as possibilidades concretas e distintas de "escolha" para as adolescentes das diferentes camadas sociais. ${ }^{6}$

Vale considerar que, na gravidez, independente da idade, a mulher passa por uma crise situacional decorrente da mudança de papel social, necessidade de novas adaptações, rea- justes interpessoais e intrapsíquicos e mudança de identidade.

Nas vivências da gravidez precoce, a adolescente defronta-se com as alterações corporais que afetam sua autoimagem e autoestima. Este estado é agravado pela insegurança no cuidado com o bebê, decorrente de sua inexperiência e imaturidade. $^{3}$

A adaptação à condição materna implica em desenvolver capacidades para prestar cuidado ao filho frágil e dependente, o que para a adolescente pode se tornar um processo ainda mais complexo, quando não obtém do seu meio relacional um suporte apropriado. Para superar as dificuldades, é comum a adolescente permanecer vivendo com a família, gerando mudanças na dinâmica familiar. ${ }^{3}$

Estudo sobre o significado da maternidade na adolescência identificou que as adolescentes têm sua capacidade subestimada para o cuidado com o filho. ${ }^{6}$ Segundo alguns autores, "a adolescente fica como expectadora e em segundo plano, entregando o filho aos cuidados de outra pessoa para deixar o bebê a salvo do que imagina ser sua incompetência". 7:12 O preconceito de ser incapaz de assumir responsabilidades maternas é fruto de uma sociedade que cobra, e ao mesmo tempo impede que essas assumam verdadeiramente seus filhos e que se sintam responsáveis por eles. ${ }^{8}$

Frente a essas considerações é que tomamos como objeto deste estudo o cotidiano de mães adolescentes quanto às vivências do cuidado materno e do autocuidado na fase puerperal. Existem poucos estudos sobre a maternidade na adolescência com enfoque qualitativo, o que sugere a necessidade de ampliar a compreensão do significado da maternidade, partindo das vivências das próprias mães adolescentes. A análise foi respaldada na concepção de maternidade não como um dado somente biológico, mas também "social múltiplo". Existem pontos de interseção do biológico, do subjetivo e do social: o desejo de reprodução da espécie; a busca de um sentido para a vida; a necessidade de valorização e de reconhecimento social. ${ }^{8}$

Este estudo trará subsídios a implementação de estratégias de intervenção nos serviços direcionando ações que sejam de efetivo suporte para as mães adolescentes, auxiliando-as nos cuidados com o bebê e em seu autocuidado. Nesse sentido, este estudo tem como objetivos: identificar os significados atribuídos pelas mães adolescentes sobre os cuidados com o bebê e seu autocuidado e 
identificar o que as mães adolescentes reconhecem como dificuldade na vivência da fase puerperal e no cuidado com o bebê.

\section{METODOLOGIA}

Trata-se de um estudo do tipo exploratóriodescritivo, com abordagem qualitativa, o que possibilita a análise subjetiva dos dados. O estudo foi realizado com adolescentes assistidas na Maternidade do Complexo Aeroporto - MATER, uma instituição filantrópica localizada na periferia do município de Ribeirão Preto, no interior do Estado de São Paulo. A idade considerada para adolescente foi de 10 a 19 anos, conforme estabelecido pela Organização Mundial da Saúde. ${ }^{9}$ As adolescentes que aceitaram participar do estudo assinaram o Termo de Consentimento Livre e Esclarecido, bem como seus responsáveis legais.

Participaram do estudo 22 puérperas adolescentes primíparas atendidas nas consultas de enfermagem no pós-parto e no grupo de puerpério da instituição referida, no período de janeiro a março de 2005. Tais consultas são agendadas a todas as mulheres assistidas na MATER que sejam residentes em Ribeirão Preto, num período de uma semana a 10 dias, após o parto. O grupo de puerpério é realizado uma vez por semana, momento em que recebem orientações referentes ao cuidado com o bebê, amamentação e demais cuidados, durante a fase puerperal.

A escolha das primíparas se justifica por ser a primeira experiência a mais carregada de inseguranças, conflitos e inexperiências quanto aos cuidados no puerpério e maternidade. Não fizeram parte da amostra mulheres que tiveram filhos prematuros, com má formação ou com qualquer intercorrência que exija cuidados especiais tanto relativos à mãe como à criança. Definimos o tamanho amostral por saturação das informações coletadas.

Para coleta dos depoimentos, utilizamos a técnica de entrevista semiestruturada, que oferece ao pesquisador flexibilidade na obtenção de informações. As entrevistas foram realizadas em local reservado na própria maternidade e gravadas, de modo a favorecer o diálogo entre as participantes e o entrevistador. Utilizamos um roteiro de perguntas com dados sociodemográficos; obstétricos e sobre as vivências do cuidado materno e do autocuidado na fase puerperal.

A análise das informações foi fundamentada na técnica de análise de conteúdo, modalidade temática. ${ }^{10} \mathrm{O}$ material foi transcrito e, posteriormente, realizamos a análise que inclui os seguintes passos: leitura inicial, procurando ter uma compreensão global do material; identificação das unidades de significado que emergiram das falas dos entrevistados; descoberta de núcleos, interpretação e discussão dos núcleos de sentido encontrados.

Em observância à determinação da Resolução No 196/96, do Conselho Nacional de Saúde, este projeto foi aprovado pelo Comitê de Ética em Pesquisa da Escola de Enfermagem de Ribeirão Preto-USP sob o protocolo No 0486/2004.

\section{RESULTADOS}

Traçando um perfil das características pessoais e sociodemográficas das 22 adolescentes entrevistadas, observamos que as mesmas têm idade que varia de 14 a 19 anos, sendo que 59\% (13) encontram-se na faixa dos 15 aos 18 anos, 54\% (12) possuem o ensino fundamental incompleto, $50 \%$ (11) não exercem nenhum tipo de trabalho remunerado, tendo suas atividades restritas ao ambiente doméstico, (35\%) exercem atividade remunerada fora do lar e apenas 14\% (três) das puérperas relataram ser estudantes. Com relação ao estado civil, 91\% (20) declararam serem legalmente solteiras, porém, destas, $65 \%$ (13) vivem em união consensual com o pai da criança; apenas $9 \%$ (duas) das entrevistadas são casadas.

No que diz respeito à renda familiar, 36\% (oito) das entrevistadas relataram possuir renda em torno de 200 a 400 reais, $27 \%$ (seis) declararam possuir renda familiar de 400 a 700 reais, 18\% (quatro) declararam renda de 700 a 1.000 reais, e apenas quatro das entrevistadas relataram possuir renda familiar acima de 1.000 reais. Quanto ao número de pessoas que residem na mesma casa, incluindo a mãe e o recém-nascido, 82\% (18) das entrevistadas vivem com três a seis pessoas, $14 \%$ (três), com sete a 10 pessoas, e 4\% (uma) declaram residir em casa com mais de 10 pessoas.

Quanto aos antecedentes obstétricos, a maioria das adolescentes, 95,45\% (21), fez pré-natal, e $71 \%$ (15) destas adolescentes que fizeram pré-natal iniciaram o acompanhamento no primeiro trimestre de gestação. Não fizeram pré-natal 4,54\% (uma) das puérperas entrevistadas.

A maioria das puérperas, $68 \%$ (15), teve parto normal, $32 \%$ (sete) fizeram cesárea. O fato de a maioria das entrevistadas ter sido submetida ao parto normal está associado à filosofia assistencial da maternidade que, como Hospital Amigo da Criança, incentiva o parto normal e o aleitamento materno. 
Por meio da análise de conteúdo das entrevistas, identificamos três categorias temáticas centrais: o significado do ser mãe adolescente: mudanças na vida pessoal e familiar; o cuidado materno e o autocuidado no puerpério; compreendendo as dificuldades e as fontes de suporte.

\section{O significado do ser mãe adolescente: mu- danças na vida pessoal e familiar}

Para a maioria das adolescentes 95,4\% (21), a maternidade trouxe mudança em suas vidas, não só restrita às modificações físicas, mas também no âmbito psicológico e social.

A mudança social se caracteriza pelo fato de que, com a maternidade, a adolescente deixa a condição de menina para adquirir o papel de mãe e mulher o que, muitas vezes, é visto por elas próprias como uma ascensão social.

Ah! Sei lá eu sou diferente hoje, parece que antes eu era uma menina mimada que fazia tudo o que dava na cabeça (e1).

Acho que cresci muito. Depois que ela nasceu passei de menina a mulher agora (e12).

A maturidade em consequência da maternidade se reflete na fala das adolescentes, quando estas relatam que agora estão mais responsáveis e mais preocupadas com o futuro frente ao desafio de criar e educar uma criança.

Agora eu me preocupo mais com as coisas, quero arruma um serviço porque antes eu só estudava, mas agora tenho que cria ele (e9).

Eu tô mais responsável, muito preocupada com o futuro, agora eu tenho um ser que depende de mim (e14).

A maternidade acarreta mudanças na rotina da família, principalmente no cotidiano da puérpera que, além dos afazeres domésticos, tem como dever os cuidados com o recém-nascido, dependente da mãe.

[...] você não tem mais liberdade, fica mais preocupada (e17).

[...] eu não vou trabalha mais, porque eu num gosto de tá deixando meu filho com os outros (e20).

Essas mudanças, tanto na condição social quanto na rotina, também vêm associadas a mudanças no psicológico dessas mães adolescentes que acabam por criar mecanismos de enfrentamento e adaptação à nova condição.

Eu tô me acostumando ainda [...] sei que é difícil tem que te calma, mas tem que enfrenta (e9).
[...] fiquei mais calma, paciente, quando você é mãe os sentimentos mudam (e15).

Para muitas das adolescentes puérperas, a maternidade lhes trouxe maior sensibilidade, paciência para enfrentar os problemas, ouvir os outros, saber lidar com as mudanças e com a abnegação que a rotina materna acaba por provocar no seu ritmo de vida e em suas próprias vontades.

\section{O cuidado materno e o autocuidado no puerpério}

\section{Cuidado materno: cuidar direitinho e no ho- rário certinho}

A grande maioria das adolescentes $95,4 \%$ (21) percebe o cuidar do bebê como um dever a ser exercido com perfeição, para que possam ser "boas mães".

Ah! Eu tenho que cuida bem dele [...] dá banho, cuida do umbigo, amamenta ele direitinho (e3).

[...] cuidar direitinho na hora do banho com o umbigo, na hora de troca e de mama também (e5).

Vale considerar que o aspecto afetivo do cuidar aparece evidenciado somente em uma das entrevistas: [...] o banho né, trocar e o carinho também que eu acho importante (e12).

Ainda, a necessidade do estabelecimento de uma rotina, a regularidade do cuidado aparece como uma tentativa das mães de organizar e facilitar seu desempenho no trabalho, o que envolve os afazeres domésticos e o cuidado com o bebê.

Meu bebê mama no horário certinho, não me deu muito trabalho não (e6).

[...] tem de tá olhando, de tá observando se tá tudo certinho (e1).

O bebê passa a se tornar o elemento fundamental da casa, e toda a rotina se altera em função de suas necessidades, em estado de vigília constante.

\section{Autocuidado no puerpério: preocupando-se com o corpo físico e pensando na saúde do filho}

Ao analisarmos as entrevistas com relação ao autocuidado no puerpério, para grande parte das adolescentes puérperas, o cuidar do corpo está associado ao desejo de que o mesmo volte às condições pré-gravídicas, uma preocupação com a beleza e a vaidade feminina se fazem presentes.

[...] vou entrar numa academia, quero cuidar do meu cabelo [...] cuida de mim (e12). 
Eu me preocupo sim quero fazer ginástica porque num quero fica com barriga (e14).

O pensar na saúde se relaciona mais ao fato de que a saúde do bebê é influenciada diretamente pela saúde da mãe, visto que a dependência do bebê com relação à mãe é maior nessa fase em função do aleitamento materno. O que também justifica a grande preocupação das mães com a alimentação.

Ah [...] só tiro as coisa mais amarga por causa do leite (e9).

Tô normal, comendo bem pra pode amamenta [...] (e11).

A mulher passa a priorizar tudo que se relaciona ao bebê, em detrimento dos cuidados consigo mesma. Este fato se evidencia na visão dicotomizada da puérpera com relação à idéia de cuidar do bebê como prioridade em relação ao autocuidado. (e11)

[...] mas agora eu penso mais é no nenê mesmo

Agora tô pensando mais no bebê só (e17).

A idéia do cuidado do bebê como prioridade também traz o caráter cultural da fragilidade e dependência do pequeno ser, e a mãe que tem como função garantir sua saúde.

\section{Compreendendo as dificuldades e as fontes de suporte}

\section{Dificuldades: falta de experiência, informa-} ção, condições sociais e financeiras

As dificuldades relatadas pelas puérperas em sua grande maioria, 90\% (20), estão relacionadas à fase de adaptação à condição de mãe, às rotinas e às demandas que a maternidade acarreta.

A inexperiência somada a pouca idade provocam, nessas mães, insegurança e medo de assumirem sozinhas os cuidados com a criança: ser mãe na minha idade é difícil, ainda mais que eu num tenho experiência (e22).

Outra dificuldade frequentemente presente nos depoimentos é a amamentação. Os motivos pelos quais as adolescentes justificam tal dificuldade são: "o nenê num pega", "meu bico rachou", "meu bico dói".

Ah! Só na hora de amamenta porque meu peito rachou e tá doendo um (e5).

Tenho pra amamenta ele num pega [...] (e16).

Em muitos relatos também podemos perceber o incômodo das puérperas adolescentes com o choro do bebê. O choro é a forma como a criança expressa que algo não está bem, seja por fome, cólica ou até mesmo irritação. Embora a maioria das adolescentes tivesse consciência dos motivos mais comuns pelos quais a criança chora, o lidar com este tipo de situação é difícil para essas mães que, muitas vezes, percebem o choro do bebê como resposta a sua incompetência em atender às necessidades da criança. Ainda, no horário noturno, o choro torna-se mais desagradável, visto que a mãe encontra-se já exausta do trabalho diário e anseia por um período de descanso.

[...] chora a noite toda dá trabalho, mas depende de como você encara [...] (e17).

Só a noite pra dormir ela chorava muito daí, às vezes eu ficava com um pouquinho de raiva (e21).

A falta de suporte social, presentes em algumas das entrevistas, é motivo de tristeza para muitas mães que gostariam de compartilhar dos prazeres e dificuldades deste momento com alguém que as compreendesse.

Eu queria que a minha irmã tivesse sempre comigo, mas num dá né (e13).

Sinto muita falta da minha mãe, ela mora longe e é difícil pra ela vim pra cá (e18).

A dificuldade financeira aparece como empecilho, para que estas mães possam oferecer condições consideradas por elas ideais para criar seu filho: dinheiro né, com dinheiro faz tudo. Aié mais uma pessoa dentro de casa que precisa até mais do que qualquer um que ta lá dentro (e4).

\section{Fontes de suporte: a experiência da família e o saber do profissional de saúde}

A maioria das adolescentes entrevistadas, $82 \%$ (18), referiu receber ajuda nas atividades práticas relativas aos afazeres de casa e aos cuidados com o bebê, sendo prestada por um familiar e/ou por alguém próximo à puérpera. $\mathrm{A}$ ajuda feminina é predominante, geralmente oferecida pela mãe da adolescente, sogra, irmãs e tias.

\section{Recebo da minha mãe e da minha tia [...] (e9).}

Da minha sogra que veio pra cá passar uns tempos comigo (e19).

Quando a ajuda masculina é citada, esta geralmente é prestada pelo companheiro, pai da criança. A ajuda proveniente do homem é mais relacionada a olhar a criança em alguns momentos: recebo do meu marido [...] ele faz o que pode, fica olhando, leva pra passear [...] (e11).

A ajuda é algo culturalmente esperado pelas adolescentes, visto que estas, no início, se consi- 
deram inseguras por não terem experiência para realizar os cuidados com o bebê sozinhas.

Ah! Normal dá uma força, que no começo a gente num tem experiência né (e1).

Ah... minha mãe vem dá banho, lava roupa [...] eu acho bom porque ela já é experiente [...] (e5).

Porém, muitas vezes, as adolescentes puérperas têm a percepção de que esta ajuda pode ser excessiva, sufocante e sentem a necessidade de reivindicar seu espaço tentando impor limites.

Ah! Eu acho que a gente tem que conversa e às vezes até impor limites né (e2).

Recebo da minha mãe ela faz tudo, acaba ficando muito em cima (...) e eu fico meio assim de briga com ela (e22).

O profissional de saúde também aparece como uma importante fonte de conhecimento e informação, para algumas das entrevistadas.

Quando eu cheguei aqui (na MATER) pra te nenê eu não sabia nada daí aprendi tudo aqui (e3).

[...] sempre que vou no médico eu pergunto tudo né (e1).

O profissional de saúde, como detentor do saber técnico e instrumental, tem participação delimitada aos espaços institucionais e pontuais. Tal condição é limitante para que se estabeleça um efetivo vínculo de confiança, além da visão predominantemente biologicista dos profissionais de saúde que dificultam a compreensão dos processos vivenciados pelas adolescentes em sua integralidade.

\section{DISCUSSÃO}

A gravidez na adolescência é um fato que tem ocorrido de maneira expressiva em nossa sociedade. No Brasil, cerca de um milhão de adolescentes entre 10 e 19 anos dão à luz todos os anos, o que corresponde a $20 \%$ do total de nascidos vivos no país. ${ }^{11}$

A maternidade é um processo de grande transformação na vida das mulheres. Este processo se torna mais complexo, quando se trata da mãe adolescente que, além de vivenciar os questionamentos e conflitos próprios da idade, se coloca frente à maternidade.

A faixa etária considerada ideal para a primeira gestação seria entre 18 e 20 anos $^{12}$ sendo que grande parte das puérperas deste estudo teve sua primeira gestação entre os 15 e 18 anos, antes do período considerado ideal para a primeira gestação.
A gravidez na adolescência é frequente em todos os níveis sociais, mas a maior incidência ocorre nas populações de baixa renda. ${ }^{13} \mathrm{Em}$ nosso estudo, identificamos que, na maioria das famílias das entrevistadas, a renda familiar média é de 200 reais para três pessoas. A gravidez na adolescência, muitas vezes, desestrutura a vida afetiva da adolescente e interfere na possibilidade de estudar e se qualificar para o trabalho. ${ }^{14}$ Indícios desta desestruturação são observados entre as adolescentes do estudo em que a maioria possuía o ensino fundamental incompleto e, $50 \%$ não exercem nenhum tipo de trabalho remunerado no mercado de trabalho. Estudo comparativo do perfil social entre mães adolescentes e adultas verificou que as mães adolescentes, com mais frequência, têm renda menor que um salário mínimo, quando comparadas às mães adultas e trabalham menos fora do lar que as adultas. ${ }^{15}$

A união consensual é a situação conjugal da maioria das adolescentes do estudo. As dificuldades na família podem levar as jovens a substituir os laços com os pais pela dependência afetiva do cônjuge. Incluem-se aqui as jovens que casam para sair de casa. ${ }^{16}$

A adesão ao pré-natal pelas adolescentes investigadas foi altamente satisfatória, visto que é comum entre adolescentes esconderem a gravidez, retardando a busca pela assistência precoce e, ain$\mathrm{da}$, a maioria das adolescentes teve parto normal. Durante muito tempo a gravidez na adolescência foi vista como um evento de risco, associado à mortalidade e morbidade materno-infantil. Entretanto, alguns autores consideram que a gravidez na adolescência se apresenta muito mais como um problema social do que biológico. ${ }^{17}$

Para as adolescentes, sujeitos deste estudo, ser mãe se reveste de intensas mudanças tanto na vida pessoal como familiar. Importante destacar que, historicamente, o impacto da gravidez na adolescência tem sido apontado como um elemento desestruturador da vida das adolescentes, entretanto, na atualidade, alguns autores referem que, muitas vezes, esta se constitui em uma possibilidade de busca da autonomia e responsabilidade, no desejo consciente de ser mãe e, até mesmo, em uma fonte de satisfação. ${ }^{18}$

Nessa mesma direção, identificamos que as mudanças na vida destas adolescentes abriram possibilidades para o crescimento pessoal, expressando-se em senso de preocupação e responsabilidade, na medida em que toma consciência da relação de dependência do filho para consigo. A 
amamentação a coloca frente ao primeiro desafio de se adaptar ao ritmo da criança, ao mesmo tempo em que emergem os sentidos mais amplos de maternidade, em que é preciso cultivar a sensibilidade e a paciência para atingir a maturidade psicológica, de modo a enfrentar os problemas, ouvir o outro e aprender a lidar com as mudanças e renúncias que a maternidade provoca em seu ritmo de vida e em suas próprias vontades.

A rotina imposta pela maternidade, segundo algumas adolescentes, traz restrições a suas vidas, fazendo com que elas percam a liberdade. A aceitação passiva e substitutiva das suas próprias aspirações em função do filho pode ter origem nos processos de socialização, quando as meninas são criadas para assumir os papéis maternos e domésticos. ${ }^{19}$

Os significados que a maternidade tem para as adolescentes mães se refletem nos sentidos que atribuem ao cuidado materno. Atrelado à concepção social de ser boa mãe, o cuidado materno é cuidar direitinho e no horário certinho. A prioridade materna é atender oportunamente às necessidades do filho, visto que a maternidade é entendida como inerente à condição feminina, cabendo às mulheres grande parte da responsabilidade de cuidado para com a criança. ${ }^{20}$ Para as adolescentes puérperas, o cuidado materno requer disciplina e vigília constantes.

Quanto ao autocuidado no pós-parto, identificamos que a preocupação com a própria saúde está prioritariamente ligada à função materna de prover à criança condições ideais para o seu desenvolvimento, principalmente no que diz respeito a sua função de nutriz. Dentre os cuidados no pós-parto a que as mulheres devem obedecer estão aqueles relacionados com a alimentação. Tal condição também foi identificada em outro estudo com puérperas, independente da idade, sobre suas vivências na amamentação. As mulheres, permeadas por um ideal de maternidade, têm seus desejos e necessidades conformados à condição de "ser o seu corpo para o filho". Entretanto, conflitos e ambivalências estão presentes, evidenciando a existência de dois conjuntos de necessidades, a da criança e a da mãe, e que a solução nem sempre se mantém colocando-se a mãe na qualidade de objeto do filho. ${ }^{21}$

Tais conflitos podem ser identificados quando manifestam o desejo da volta do corpo às condições pré-gravídicas, como finalidade de desenvolver o cuidado para si, o que acreditamos estar relacionado com a fase da adolescência em que, com mais intensidade, o culto ao corpo físico tem expressão no seu modo de viver. Estudo sobre as concepções de adolescentes sobre saúde e articulação com suas práticas de cuidado, não específica à fase pós-parto, mostrou que a saúde e o cuidado emergem de um modo de viver a vida, do livre arbítrio, ainda que se reconheça que tais escolhas podem não ser as melhores ou mais recomendáveis, de acordo com um determinado parâmetro, aprendido na vida sociofamiliar. ${ }^{22}$

Dentre as dificuldades relatadas pelas adolescentes, a falta de experiência e de conhecimento são fatores limitantes no desempenho da maternidade, particularmente relacionados à amamentação. Inseguranças e incômodo frente ao choro do bebê faz emergir sentimentos de incompetência para o cuidado materno e a necessidade de apoio de seu meio relacional. A dificuldade financeira é tida como um empecilho, para que elas possam criar a criança da maneira que desejam.

Alguns estudos mostram que as adolescentes, ao se sentirem seguras e apoiadas para prestar cuidados aos filhos, têm fortalecido o vínculo com o bebê e demonstram maior amadurecimento e responsabilidade. ${ }^{3}$ Sobre o que consideram como fonte de suporte frente às vivências da fase em que se encontram, a família é o principal referencial de apoio para estas adolescentes. A experiência e os conhecimentos de outras mulheres da família que já vivenciaram o puerpério se fazem importantes na construção do ser mãe. O aprendizado acerca dos cuidados está estreitamente ligado com a transmissão da experiência já vivida, fazendo com que as filhas apoiem-se nos exemplos e ensinamentos de suas mães, repetindo a vivência dessas como modelo a ser seguido. ${ }^{23}$

Sobre o apoio da família, algumas adolescentes puérperas se sentem incomodadas pelo fato de acabarem sendo expectadoras no cuidado com a criança, não possuindo autonomia sobre o próprio filho. Tal fato também foi observado por outros autores, os quais consideram que os vínculos formados pelas ligações afetivas e relações de proximidade têm importante peso nas escolhas e decisão das mulheres ante as práticas de cuidado materno. ${ }^{25}$

O profissional de saúde é citado como fonte de suporte por poucas adolescentes puérperas estudadas. Sobre tal participação, autores têm considerado que o profissional, como agente nas práticas de cuidado, desempenha ações prescritivas, impositivas e de supervisão, o que faz menção a uma postura de detentor do saber. ${ }^{21}$ A busca pelo profissional de saúde está na dependência de uma outra lógica, ou seja, do que significam como patológico, que traz dano à saúde. ${ }^{24}$ 


\section{CONSIDERAÇÕES FINAIS}

A maternidade para as adolescentes deste estudo trouxe intensas mudanças em suas vidas pessoal e familiar, cuja adaptação tem evocado sentimentos inerentes e necessários à compreensão de sua condição de mãe.

Sobre o significado que atribuem aos cuidados com o filho, perpassam os imperativos sociais e simbólicos de ter como prioridade o atendimento das necessidades da criança, como condição emblemática para ser considerada uma boa mãe. Entretanto, vale considerar que a sociedade atribui à adolescente uma capacidade subestimada para cuidar do filho e, muitas vezes, a impede de assumir as responsabilidades e demandas da maternidade com tranqüilidade.

Ancorado no mesmo universo moral de boa mãe, a preocupação com o cuidado de si tem por finalidade atender às necessidades do filho. Tais elementos podem ser úteis na tomada de consciência das mulheres para a importância do autocuidado, na fase puerperal.

A família exerce um papel fundamental de apoio e suporte nesta fase de aprendizado e adaptação. Neste sentido, importante estimular os familiares, para que sua participação seja de maneira a promover a independência precoce da puérpera adolescente no cuidado com o filho, bem como possibilite a ela construir-se satisfatoriamente no papel de mãe.

A importante participação do profissional de saúde é compartilhar o conhecimento e ações que favoreça a autonomia das mesmas no cuidado. Alternativas que surgem no contexto assistencial são os cursos preparatórios, chamados "cursos de gestantes", onde se discuti os temas referente a gravidez, parto e puerpério, fazendo uso de uma linguagem mais dinâmica e participativa como meio de sensibilizar estas adolescentes e seus familiares a fim de que este processo ocorra de maneira mais natural e sadia. Proporcionando também o aprendizado as jovens mães, as consultas de enfermagem no puerpério constituem-se de alternativa de apoio na fase pós-parto, para sanar as possíveis dúvidas e dificuldades que possam se apresentar.

\section{REFERÊNCIAS}

1. Stern C, Garcia E. Hacia un Nuevo Enfoque en el Campo del Embarazo Adolescente. Reflexiones. Sexualidad, salud y reproducción 13. México (MX): Programa Salud Reproductiva y Sociedad/El Colegio de México. 1999.
2. Trindade RFC. Gravidez na adolescência: análise do padrão reprodutivo [dissertação]. Ribeirão Preto (SP): Universidade de São Paulo. Escola de Enfermagem de Ribeirão Preto; 2001.

3. Folle E, Geib LTC. Representações sociais das primíparas adolescentes sobre o cuidado materno ao recém-nascido. Rev Latino-am Enfermagem. 2004 Mar-Abr; 12(2):183-90.

4. Santos SR, Schor N. Vivências da maternidade na adolescência precoce. Rev Saúde Pública. 2003 Fev; 37(1):15-23.

5. Souza MMC. A maternidade nas mulheres de 15 a 19 anos: um retrato da realidade. O mundo da Saúde. 1999 Mar-Abr; 23(2):93-105.

6. Madeira AFM. Crescer com o filho-singularidade do adolescer mãe [tese]. São Paulo (SP): Universidade de São Paulo. Escola de Enfermagem; 1998.

7. Machado FN, Meira DCS, Madeira AM.F. Percepções da família sobre a forma como a adolescente cuida do filho. Rev Esc Enferm USP. 2003 Mar; 37(1):11-8.

8. Scavone L. Dar a vida e cuidar da vida: feminismos e ciências sociais. São Paulo (SP): Editora UNESP, 2004.

9. Organización Mundial de la Salud (OMS). Salud de los jóvenes - un reto y una esperanza. Genebra (SZ): OMS; 1995.

10. Minayo MC. O desafio do conhecimento: pesquisa qualitativa em saúde. São Paulo - Rio de Janeiro (RJ): Hucitec-Abrasco; 1996.

11. Almeida MS. A mulher e sua "destinação" à maternidade. Rev Baiana de Enfermagem. 1996 Abr; 9(1):43-51.

12. Neme B. Obstetrícia básica. $2^{a}$ ed. São Paulo (SP): Sarvier, 2000.

13. Gama SGN, Szwarcwald CL, Leal MC, Theme Filha MM. Gravidez na adolescência como fator de risco para baixo peso ao nascer no Município do Rio de Janeiro, 1996 a 1998. Rev. Saúde Pública. 2001 Fev; 35(1):74-80.

14. Rea MF. Gravidez, parto, puerpério e amamentação. In: Berquó E, organizador. Sexo \& Vida: panorama da saúde reprodutiva no Brasil. Campinas (SP): Editora da UNICAMP; 2003. p.197-227.

15. Vieira LF, Pinto e Silva JLC, Barros Filho AAB. A amamentação e a alimentação complementar de filhos de mães adolescentes são diferentes das de filhos de mães adultas? J Pediatr. 2003; 79:317-26.

16. Adamo FA. Sexualidade: alguns aspectos. In: Saito MI, Silva LEV. Adolescência: prevenção e riscos. São Paulo (SP): Atheneu; 2001. p. 115-9.

17. Gama SGN, Szwarcwald CL, Leal MC. Experiência de gravidez na adolescência, fatores associados e resultados perinatais entre puérperas de baixa renda. Cad Saúde Pública. 2002 Jan-Fev;18(1):153-61.

18. Gontijo DT, Medeiros M. "Tava morta e revivi": significado de maternidade para adolescentes com 
experiência de vida nas ruas. Cad Saúde Pública. 2008 Fev; 24(2):469-72.

19. Del Priore M. Ao sul do corpo: condição feminina, maternidade e mentalidades no Brasil colônia. Rio de Janeiro (RJ): José Olympio; 1993.

20. Moreira KFA. Aleitamento materno à luz dos direitos reprodutivos da mulher: afinal do que se trata? [tese]. Ribeirão Preto (SP): Universidade de São Paulo. Escola de Enfermagem de Ribeirão Preto; 2003.

21. Nakano, AMS. As vivências da amamentação para um grupo de mulheres: nos limites de ser "o corpo para o filho" e de ser "o corpo para si". Cad Saúde Pública. 2003; 19(2):p.S355-63.
22. Ferreira MA, Alvim NAT, Teixeira MLO, Veloso RC. Saberes de adolescentes: estilo de vida e cuidado à saúde. Texto Contexto Enferm. 2007 Jun; 16(2):217-24.

23. Machado ARM. O lugar da mãe na prática da amamentação de sua filha nutriz: o estar junto. [dissertação]. Ribeirão Preto (SP): Universidade de São Paulo. Escola de Enfermagem de Ribeirão Preto; 2001.

24. Nakano AMS, Reis MCG, Pereira MJB, Gomes FA. O espaço social das mulheres e a referência para o cuidado na prática da amamentação. Rev Latino-am Enfermagem. 2007; 15:230-8. 